\title{
Expanded validation of the effect and quality of a pathogen inactivation system based on riboflavin photochemistry on platelet bacterial contamination
}

\author{
Bin Fan ${ }^{1, \#}$, Meng Yi ${ }^{2 \#}$, Guang Yang ${ }^{3}$, Lu Yang ${ }^{2}$, Wei Shang ${ }^{2}$, Yi Liu ${ }^{2}$, Xiaolong Zhong ${ }^{1}$, Liguo Zhu ${ }^{2,4}$, \\ Deqing Wang ${ }^{1,2}$
}

${ }^{1}$ Department of Blood Transfusion, Affiliated Hospital of Southwest Medical University, Luzhou, China; ${ }^{2}$ Department of Blood Transfusion Medicine, The First Medical Center, Chinese PLA General Hospital, Beijing, China; ${ }^{3}$ Department of Laboratory, The Red Cross (SEN GONG GENERAL) Hospital of Heilongjiang, Heilongjiang, China; ${ }^{4}$ Department of Blood Transfusion, Qilu Hospital (Qingdao), Cheeloo College of Medicine, Shandong University, Qingdao, China

Contributions: (I) Conception and design: D Wang, B Fan, M Yi, L Zhu; (II) Administrative support: D Wang; (III) Provision of study materials or patients: Y Liu; (IV) Collection and assembly of data: L Yang, W Shang; (V) Data analysis and interpretation: X Zhong; (VI) Manuscript writing: All authors; (VII) Final approval of manuscript: All authors.

\#These authors contributed equally to this work.

Correspondence to: Deqing Wang. The First Medical Center of the General Hospital of the People's Liberation Army, No. 28 Fuxing Road, Haidian District, Beijing, China. Email: deqingw@vip.sina.com; Liguo Zhu. Department of Blood Transfusion, Qilu Hospital (Qingdao), Cheeloo College of Medicine, Shandong University, 758 Hefei Road, Qingdao 266035, China. Email: zhu_li_guo@sina.com.

Background: Bacterial contamination still poses serious challenges to blood safety. Platelets have the highest bacterial contamination risk of all blood components.

Methods: Twenty units of manual platelets were prepared from blood donated by our hospital, which were inoculated with Staphylococcus aureus and Escherichia coli suspensions. The riboflavin sodium phosphate solution was added into platelets, adjusted to a final concentration of $160 \mu \mathrm{mol} / \mathrm{L}$. Platelets added into an illumination bag and placed in the inactivation system for riboflavin photochemistry at various doses. The inactivation effect of bacteria was evaluated on a Columbia blood agar plate by the plate counting method. Meanwhile, the blood routine, blood gas analysis, platelet aggregation test, and thromboelastogram of platelets before and after treatment were detected to evaluate the changes of platelet quality after treatment. Results: the inactivation effect of $S$. aureus and $E$. coli at the inactivation dose $\left(16.9 \mathrm{~J} / \mathrm{cm}^{2}\right)$ could reach more than 4 logs. After treatment at $16.9 \mathrm{~J} / \mathrm{cm}^{2}$, the blood routine results showed that the platelet count was significantly different $(\mathrm{P}<0.05)$, and the blood gas analysis showed that the oxygen partial pressure $\left(\mathrm{pO}_{2}\right)$ and lactic acid concentration $(\mathrm{cLac})$ were also significantly different $(\mathrm{P}<0.05)$. After $16.9 \mathrm{~J} / \mathrm{cm}^{2}$ treatment, there was a significant difference between Arachidonic acid (AA) and Collagen (Cog) activator groups in the platelet aggregation experiment $(\mathrm{P}<0.05)$, but there was no significant difference in the main thrombelastogram (TEG) parameters ( $\mathrm{R}$ value, $\mathrm{K}$ value, angle value, $\mathrm{MA}$ value) after treatment $(\mathrm{P}>0.05)$.

Conclusions: The inactivation effect of this set of blood component pathogen inactivation system on platelet bacterial contamination could be considered to meet actual clinical needs, with the inactivation treatment having little impact on platelet function.

Keywords: Platelet bacterial contamination; riboflavin photochemistry; pathogen removal techniques; pathogen inactivation; platelet function

Submitted Oct 18, 2021. Accepted for publication Nov 24, 2021.

doi: $10.21037 / \mathrm{atm}-21-5834$

View this article at: https://dx.doi.org/10.21037/atm-21-5834 


\section{Introduction}

The safety of allogeneic blood products has improved dramatically with significant improvements in donor screening and pathogen detection technologies, but the potential risk of viral, bacterial, and other pathogen infection remains (1). Bacterial contamination of platelets is a major risk for infection in blood transfusions, and platelet transfusions are more likely than any other blood products to cause infections, septicemia, or death (2). Skin microflora is the main source of bacterial contamination. Platelet storage condition of an air-permeable bag that oscillates continuously at room temperature $\left(20-24{ }^{\circ} \mathrm{C}\right)$ could effectively support bacterial growth (3). A significant portion of the bacterial species contaminating platelets can form biofilms, and such multicellular aggregates are typically encapsulated in an extracellular matrix that can adhere to biological and nonbiological surfaces and evade detection by culture screening systems based on supernatant sampling (4). According to reports, the frequency of bacterial contamination of platelets ranges from $1: 1,000$ to $1: 2,500$. Studies have shown that for hematological patients and tumor patients who receive an average of 6 units of apheresis platelets per treatment period, the risk of contaminated platelets transfusion is $1: 250$ and the risk of infectious transfusion reaction is $1: 1,000(5,6)$. Therefore, the treatment of platelets with pathogen inactivation techniques is necessary. In recent years, various photochemical techniques using UV or visible light have been developed to inactivate pathogens in blood components; these include the INTERCEPT Blood System for Platelets (Cerus Corporation, Concord, CA, USA) (7); the Mirasol Pathogen Reduction Technology system (Terumo BCT, Lakewood, CO, USA) (8), and the THERAFLEX UV-Platelets system (MacoPharma, Mouvaux, France) (9). Riboflavin photochemistry is an emerging blood pathogen inactivation method that combines riboflavin with light (such as ultraviolet). Riboflavin, also known as vitamin $\mathrm{B}_{2}$, can be embedded into the DNA double helix structure. Under the irradiation of light or ultraviolet light, riboflavin will induce irreversible decomposition, leading to DNA double-strand break and irreversible damage. The normal riboflavin concentration level in human blood is $100-400 \mathrm{ng} / \mathrm{mL}$, so the trace riboflavin added in the treatment can not be removed, and the riboflavin photochemical method has the advantages of wide inactivated virus spectrum, good inactivation effect, safety and reliability, high stability of protein in platelet after treatment. The Mirasol Pathogen Reduction Technology system is an inactivation system based on riboflavin photochemical method, but there are no related products used clinically in China. The blood component inactivation system based on the riboflavin photochemical method developed by our research group in the early stage can inactivate the pathogens of platelet products. In this system, riboflavin sodium phosphate solution was used as the photosensitizer, and the UVA and UVB mixed light sources were used for irradiation treatment. In this study, manual platelet mixing was used to verify the inactivation effect of the pathogen inactivation system for blood components developed in the early stage, and the quality of treated platelets and coagulation-related indicators was tested to comprehensively evaluate their inactivation effect.

We present the following article in accordance with the MDAR reporting checklist (available at https://dx.doi. org/10.21037/atm-21-5834).

\section{Methods}

\section{Bacterial culture and manual platelet preparation}

Two strains of Staphylococcus aureus (ATCC25923) and Escherichia coli (ATCC25922) were obtained from the Department of Microbiology, General Hospital of the People's Liberation Army; identified by a drug sensitivity test; and cultured in the Department of Microbiology, General Hospital of the People's Liberation Army. Prior to the experiment, individual colonies of the 2 species were isolated on Columbia blood agar plates. The separation of platelets (i.e., platelet-rich plasma) from whole blood donated by the Blood Transfusion Department of the General Hospital of the People's Liberation Army of China was completed by preparing platelet concentrates using a centrifuge (Cryofuge 6000i, Thermo Fisher Scientific, Waltham, MA, USA) and the white membrane layer of an automated blood component separator (CompoMat G5, Fresenius Kabi, Germany). First, whole blood was centrifuged at 2,600 $\mathrm{G}$ for 15 minutes to remove the red blood cells, and plasma and leukocyte membrane layers were collected. Next, the plasma and the leukocyte membranes were centrifuged at $200 \mathrm{G}$ for 10 minutes to remove the leukocyte, and platelet-rich plasma was obtained. Platelet volumes of approximately 50 to $60 \mathrm{~mL}$ and platelet concentrations of 500 to $800 \times 10^{9} / \mathrm{L}$ were collected from $400 \mathrm{~mL}$ of whole blood and measured by a blood counting system (XS-990i, Sysmex, Hyogo, Japan) 
and stored with shaking at $22{ }^{\circ} \mathrm{C}$. Platelets collected from 4 aliquots of isotype $400 \mathrm{~mL}$ whole blood were pooled into a single unit of handcrafted platelets with a capacity of $250 \mathrm{~mL}$. According to this method, 20 units of manual platelets were prepared for subsequent experiments. The Institutional Ethics Committee of Chinese PLA General Hospital (CPGH) approved this study (No. S2020-270-01). The study was conducted in accordance with the Declaration of Helsinki (as revised in 2013). There are no clinical subjects involved in this study, so there is no need to provide informed consent.

\section{Bacterial-containing platelet preparation}

Individual colonies of $S$. aureus or E. coli were selected to prepare a bacterial suspension, which was measured and adjusted for concentration using the DESMAT instrument (DenisiCHEK-plus, BioMerieux, Marcy-l'Étoile, France). A DESMAT value of 0.5 is approximately equal to a bacterial concentration of $1 \times 10^{8} / \mathrm{mL}$. The bacterial suspension was then diluted to $1 \times 10^{5} / \mathrm{mL}$ with $0.45 \%$ saline. Finally, platelets were added in a 1:10 ratio to the bacterial suspension, and the final concentration of the bacterial suspension in plasma or platelets was approximately $1 \times 10^{4} / \mathrm{mL}$.

\section{Inactivation process and inactivation effect determination}

Platelets containing S. aureus or E. coli were injected into a $250 \mathrm{~mL}$ illumination bag made of an ethylene-vinyl acetate copolymer material that had a higher UV transmittance than other materials. Then, $5 \mathrm{~mL}$ of riboflavin sodium phosphate at a concentration of $8,000 \mu \mathrm{mol} / \mathrm{L}$ (Jiangxi Pharmaceutical, Jingdezhen, China) was added to an illuminated bag containing $250 \mathrm{~mL}$ of platelets, giving a final riboflavin sodium phosphate concentration of $160 \mu \mathrm{mol} / \mathrm{L}$. The illumination bags were placed on a quartz plate and exposed to an independently developed pathogen inactivation system for blood components. Untreated platelet and platelets treat with different doses of blood component pathogen inactivation system were inoculated on colombian blood agar plate for culture for 24 hours respectively, and that bacterial count in the platelets was calculated by the following formula: bacteria per $\mathrm{mL}$ of platelet $=$ bacterial count by plate counting $\times$ the volume of platelets seeded on the plate. Inactivation effects are expressed as "logs" and are based on the log reduction in the number of bacteria contained in platelets compared to untreated platelets treated with different doses.

\section{Determination of platelet quality and function}

Platelet parameters were measured by a hematology analyzer (XS-990i, Sysmex), and 3 major platelet parameters were recorded, including platelet count (PLT), mean platelet volume (MPV), and platelet distribution width (PDW). Blood gas indicators were measured by a blood gas analyzer (ABL9, Radiometer Medical ApS, Copenhagen, Denmark), and 4 blood gas parameters were recorded, including partial pressure of oxygen $\left(\mathrm{pO}_{2}\right)$, partial pressure of carbon dioxide $\left(\mathrm{pCO}_{2}\right), \mathrm{pH}$, and lactic acid concentration (cLac). The platelet aggregation function was detected by a platelet aggregation meter (AggRAM, Helena Laboratories, Beaumont, TX, USA), and platelet aggregation function under 4 activators [Adenosine diphosphate (ADP), AA, Cog, and Epinephrine (EPI)] was detected. Kaolin thrombelastogram (TEG) was tested on a thromboelastometer (TEG5000, Haemonetics Corporation, Boston, MA, USA) after platelet-packed red blood cells of the same type were mixed with platelets in a ratio of $6: 4$.

\section{Statistical analysis}

Each experiment and test were performed at least 3 times, and the mean and standard deviation were calculated. The $t$-test of paired samples was adopted, and SPSS 17.0 (IBM Corp., Armonk, NY, USA) was used to analyze the differences. A significant difference was considered to be present when the $\mathrm{P}$ value was less than 0.05 .

\section{Results}

\section{Effects of different doses of riboflavin photochemical treatment on bacterial inactivation in platelets}

In this study, the ultraviolet fluorescent lamp with a light intensity of $14.06 \mathrm{~mW} / \mathrm{cm}^{2}$ was used in the blood pathogen inactivation system. Five doses of $8.44 \mathrm{~J} / \mathrm{cm}^{2}$ (exposure for 10 minutes), $12.7 \mathrm{~J} / \mathrm{cm}^{2}$ (exposure for 15 minutes), $16.9 \mathrm{~J} / \mathrm{cm}^{2}$ (exposure for 20 minutes), $21.1 \mathrm{~J} / \mathrm{cm}^{2}$ (exposure for 25 minutes), and $25.3 \mathrm{~J} / \mathrm{cm}^{2}$ (exposure for 30 minutes) were used to observe the inactivation effects of $S$. aureus and $S$. aureus in platelets (Figure 1). The colonies of $S$. aureus and $S$. aureus decreased by 1.5 and $1.5 \mathrm{logs}$, respectively, at $8.44 \mathrm{~J} / \mathrm{cm}^{2}$ (exposure for 10 minutes). After treatment with $12.7 \mathrm{~J} / \mathrm{cm}^{2}$ (exposure for 15 minutes), the colony pairs 

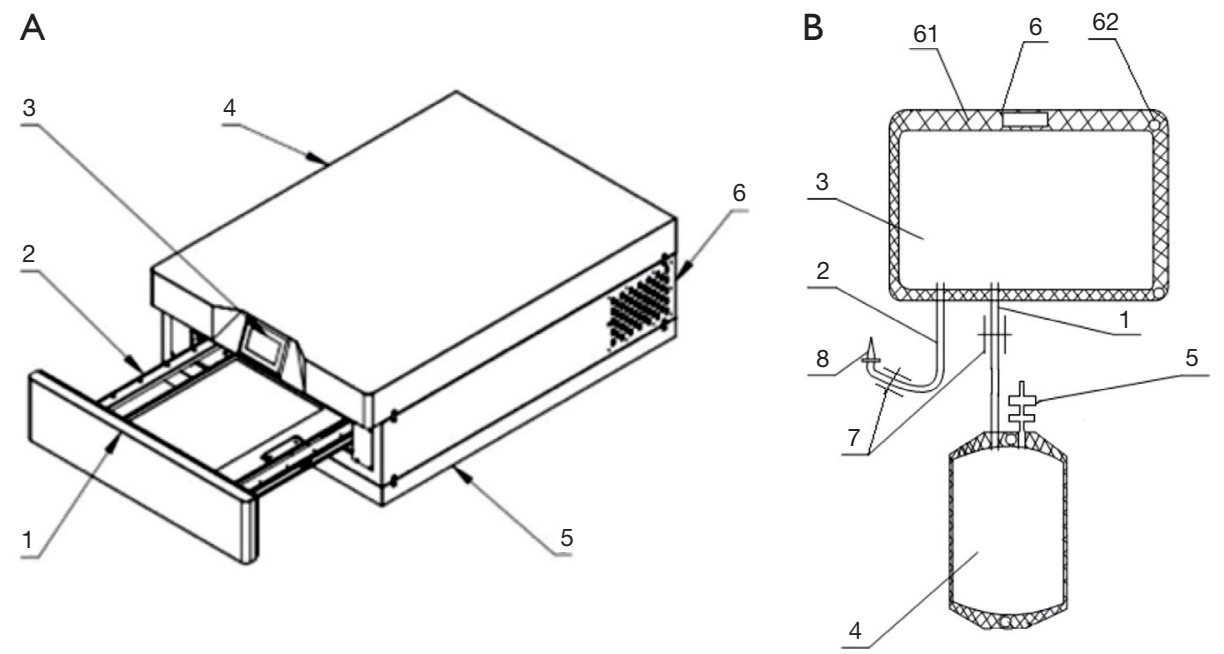

Figure 1 Schematic diagram of the inactivating instrument and blood bag. (A) Inactivating instrument: [1] cabin door, [2] tray, [3] display, [4] cabinet, [5] base, and [6] air outlet. (B) Blood bag: [1] connecting tube, [2] injection tube, [3] light treatment bag, [4] platelet storage bag, [5] blood transfusion port, [6] fixing part, [61] cardboard, [62] through hole, [7] check valve [8], and puncture needle.

were decreased by 3 logs and 2.9 logs. After treatment with $16.9 \mathrm{~J} / \mathrm{cm}^{2}$ (exposure for 20 minutes), $21.1 \mathrm{~J} / \mathrm{cm}^{2}$ (exposure for 25 minutes), and $25.3 \mathrm{~J} / \mathrm{cm}^{2}$ (exposure for 30 minutes), the colony pairs were reduced by more than 4 logs (Figure 2).

\section{Effect of different doses of riboflavin photochemical treatment on platelet quality parameter}

Different platelet parameters had different sensitivities to riboflavin photochemical treatment. There was no significant difference in PDW after 5 doses of treatment $(\mathrm{P}>0.05)$. The difference in mean platelet volume (MPV) was statistically significant at $25.3 \mathrm{~J} / \mathrm{cm}^{2}$ (exposure 30 minutes; $\mathrm{P}<0.05)$ and platelet counts were statistically significant at $16.9 \mathrm{~J} / \mathrm{cm}^{2}$ (exposure 20 minutes) and higher $(\mathrm{P}<0.05)$, with a platelet count retention rate of approximately $85 \%$ after $16.9 \mathrm{~J} / \mathrm{cm}^{2}$ (exposure 20 minutes). The results of blood gas analysis after treatment with $16.9 \mathrm{~J} / \mathrm{cm}^{2}$ (20 minutes exposure) showed that there were no significant differences in $\mathrm{pH}$ and partial pressure of carbon dioxide $\left(\mathrm{pCO}_{2} ; \mathrm{P}>0.05\right)$, while there were significant differences in partial pressure of oxygen $\left(\mathrm{pO}_{2}\right)$ and lactic acid concentration (cLac; $\mathrm{P}<0.05$; Figure 3).

\section{Effects of different doses of riboflavin photochemical treatment on platelet function}

The results of platelet aggregation showed that after treatment with $16.9 \mathrm{~J} / \mathrm{cm}^{2}$ (exposure 20 minutes), there was no significant difference between the ADP and EPI activator groups $(\mathrm{P}>0.05)$, while the difference between the $\mathrm{AA}$ and $\mathrm{Cog}$ activator groups was statistically significant $(\mathrm{P}<0.05$; Figure 4$)$. The results of TEG were as follows: before and after treatment with $16.9 \mathrm{~J} / \mathrm{cm}^{2}$ (exposure for 20 minutes), there was no significant difference in the trend of graphical curves and main parameters ( $\mathrm{R}$ value, $\mathrm{K}$ value, angle and MA value; $\mathrm{P}>0.05$; Figure 5).

\section{Discussion}

Platelet transfusions carry a greater risk of infection, sepsis, and death than any other blood product due to bacterial contamination. Skin microflora is a major source of bacterial contamination, and the storage conditions of platelets effectively support bacterial growth (10). Transfusiontransmitted bacterial infections (TTBI) and septic transfusion reactions (STRs) are major sources of morbidity and mortality after platelet transfusion (11-13). Transfusion medicine traditionally relies on methods that help avoid bacterial contamination during blood collection, handling, and transfusion, and donor selection is a first-line precaution to assess possible bacterial infections by assessing the current health of the donor and antibiotic therapy $(14,15)$.

The detection of bacteria within a predetermined hour of platelet collection has been the primary method for detecting bacterial contamination of platelets. However, 

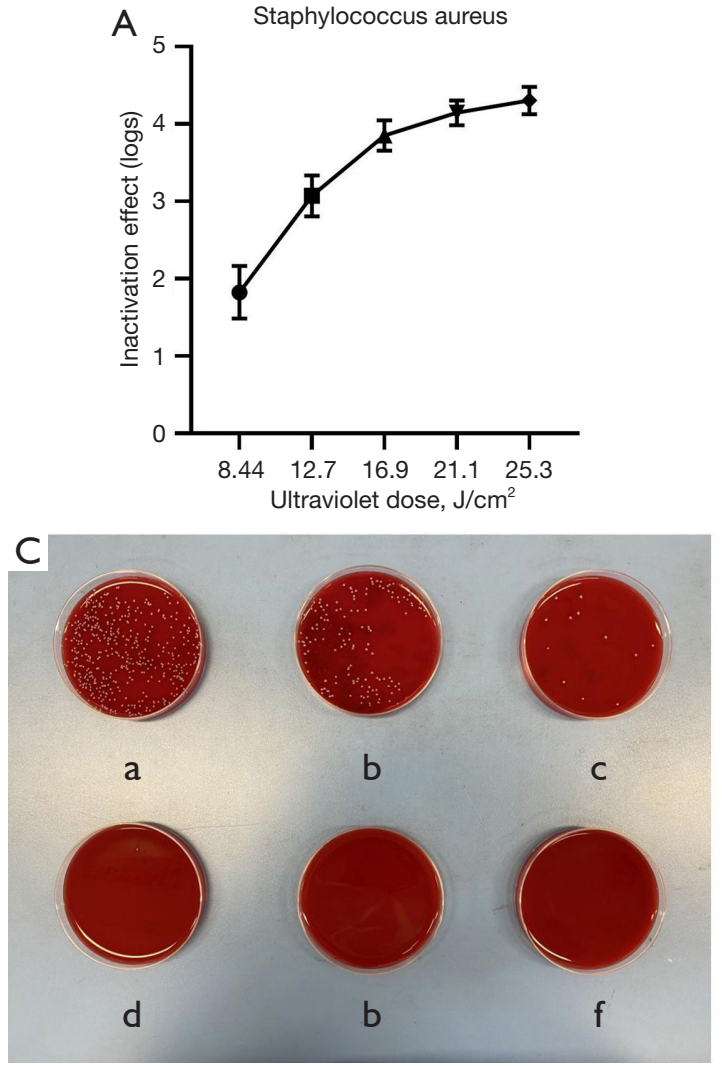

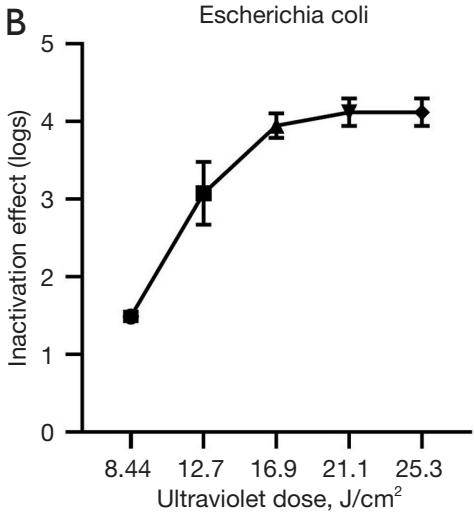

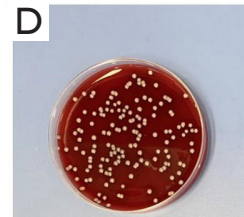

a

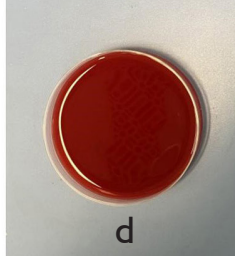

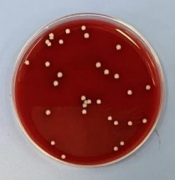

b

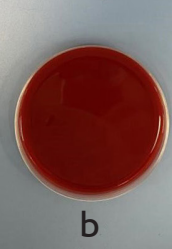

C

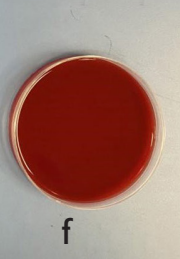

Figure 2 Inactivation effect by different doses. (A) Staphylococcus aureus inactivation effect. (B) Escherichia coli inactivation effect. (C) Colony growth after inactivation of Staphylococcus aureus by different doses: (a) $0 \mathrm{~J} / \mathrm{cm}^{2}$, (b) $8.44 \mathrm{~J} / \mathrm{cm}^{2}$, (c) $12.7 \mathrm{~J} / \mathrm{cm}^{2}$, (d) $16.9 \mathrm{~J} / \mathrm{cm}^{2}$, (e) $21.1 \mathrm{~J} / \mathrm{cm}^{2}$, and (f) $25.3 \mathrm{~J} / \mathrm{cm}^{2}$. (D) Colony growth after inactivation of Escherichia coli by different doses: (a) $0 \mathrm{~J} / \mathrm{cm}^{2}$, (b) $8.44 \mathrm{~J} / \mathrm{cm}^{2},(\mathrm{c}) 12.7 \mathrm{~J} / \mathrm{cm}^{2}$, (d) $16.9 \mathrm{~J} / \mathrm{cm}^{2}$, (e) $21.1 \mathrm{~J} / \mathrm{cm}^{2}$, and (f) $25.3 \mathrm{~J} / \mathrm{cm}^{2}$. The error bars represent standard deviations.

the sensitivity of primary bacterial culture screening is only $22-40 \%$ (16). Due to the small initial amount of bacteria contaminate in platelet donation, there is a risk of sampling error in the culture-based detection system, and due to the focus of the method on aerobic species and anaerobes, facultative and fastidious bacteria may not be detected, especially at low concentrations (17). Other techniques, such as Bac'Tx assay (Immunetics, Marlborough, MA, USA), target bacterial cell walls/membranes and components of intracellular molecules or use the colorimetric assay detect the bacterial peptidoglycan for the detection of contaminating bacteria, which is US Food and Drug Administration FDA approved for the detection of bacterial contamination in platelets (18). The disadvantages of such methods lie in the time, cost, and inventory management requirements of testing.

Unlike the detection of bacterial contamination, pathogen reduction/inactivation techniques enable the reduction of contaminants in blood components and the prevention of transfusion-transmitted infections. These technologies not only target bacteria, but also reduce the risks associated with viruses, parasites, and white blood cells. At present, 3 related products are mainly used for platelet bacterial inactivation in the world: the INTERCEPT Blood System for Platelets (Cerus Corporation), the Mirasol Pathogen Reduction Technology system (Terumo BCT), and the THERAFLEX UV-Platelets system (MacoPharma). However, there are no related products on the market in China. In the previous stage, our research group independently designed and developed a blood component pathogen inactivation instrument based on riboflavin photochemistry and its matching blood bag processing. The normal riboflavin concentration level in human blood is $100-400 \mathrm{ng} / \mathrm{mL}$, so the trace riboflavin added in the treatment can not be removed. Compared to other pathogen inactivation system, the riboflavin photochemical method 

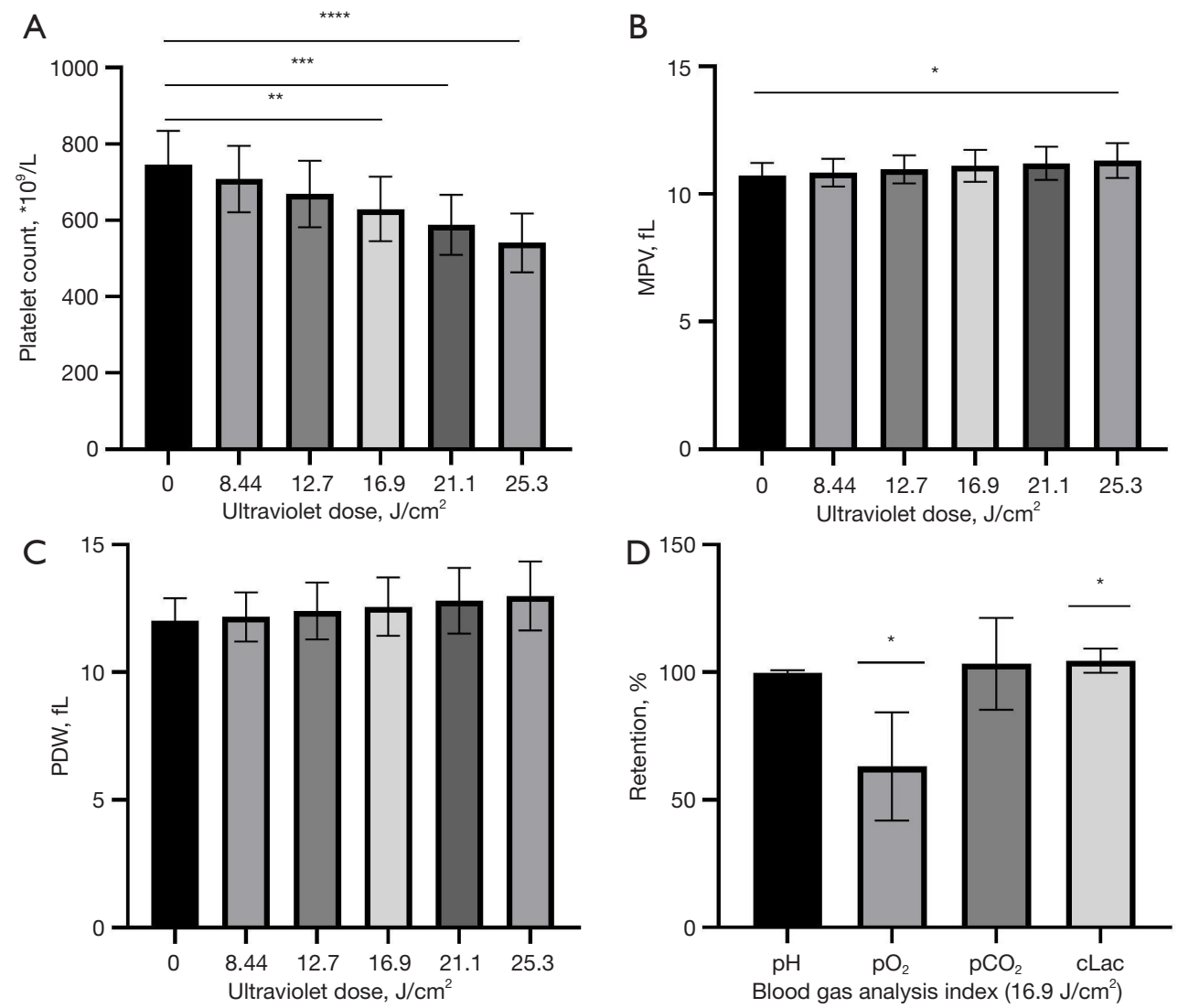

Figure 3 Routine blood test and blood gas test after different doses of treatment. (A) Platelet count (PLT). (B) Mean platelet volume (MPV). (C) Platelet distribution width (PDW). (D) Blood gas indexes ( $\left.\mathrm{pH}, \mathrm{pO}_{2}, \mathrm{pCO}_{2}, \mathrm{cLac}\right)$ after $16.9 \mathrm{~J} / \mathrm{cm}^{2}$ treatment. The error bars represent standard deviations. Significance of differences from $0 \mathrm{~J} / \mathrm{cm}^{2}$ for the corresponding cytokine is indicated by ${ }^{*}, \mathrm{P}<0.05$ or ${ }^{* *}, \mathrm{P}<0.005$ or ${ }^{* * *}$, $\mathrm{P}<0.0005$ or ${ }^{* * *}, \mathrm{P}<0.00005$.

has the advantages of wide inactivated virus spectrum, good inactivation effect, safety and reliability, high stability of protein in platelet after treatment. The structural diagram is shown in Figure 1. The inactivation instrument mainly consists of an illumination system, a vibration system, a temperature control system, and a mechanical system, with the dose rate of the machine being $14.06 \mathrm{~mW} / \mathrm{cm}^{2}$. The blood bag for treatment is mainly composed of an illumination bag made of ethylene-vinyl acetate copolymer and a normal temperature storage bag for platelets. In order to verify the inactivation effect of this inactivation system on platelet bacterial contamination, 20 units of manually prepared platelets were inoculated with 10 units of Gram-positive bacteria (S. aureus) and 10 units of Gramnegative bacteria (E. coli), respectively, to compare the inactivation effect after treatment and its impact on platelet quality and function. After treatment with $16.9 \mathrm{~J} / \mathrm{cm}^{2}$ and greater doses, the inactivation effect was comparable to that of the 3 international inactivation systems, and the system could achieve the inactivation effect of $4 \operatorname{logs}$ for S. aureus and E. coli. It should be noted that the initial titer of bacterial suspension in this study was about $1 \times 10^{4} / \mathrm{mL}$, which was much higher than that of an actual clinical situation. For blood component contamination, the titer of contamination was 10-100 CFU/unit with a unit volume of 200 to $300 \mathrm{~mL}$ (19). In practice, blood components, especially platelets, are usually prepared or processed within 4 hours of collection of whole blood. Bacterial titers did not exceed $1 \times 10^{4} / \mathrm{mL}$ even after 4 hours of bacterial binary growth (20). Therefore, the inactivation effects of 4 logs in this experiment were considered to be effective in clinical practice. Kwon et al. (21) compared the inactivation of platelet pathogen contamination with the Mirasol Pathogen Reduction Technology system and the INTERCEPT 

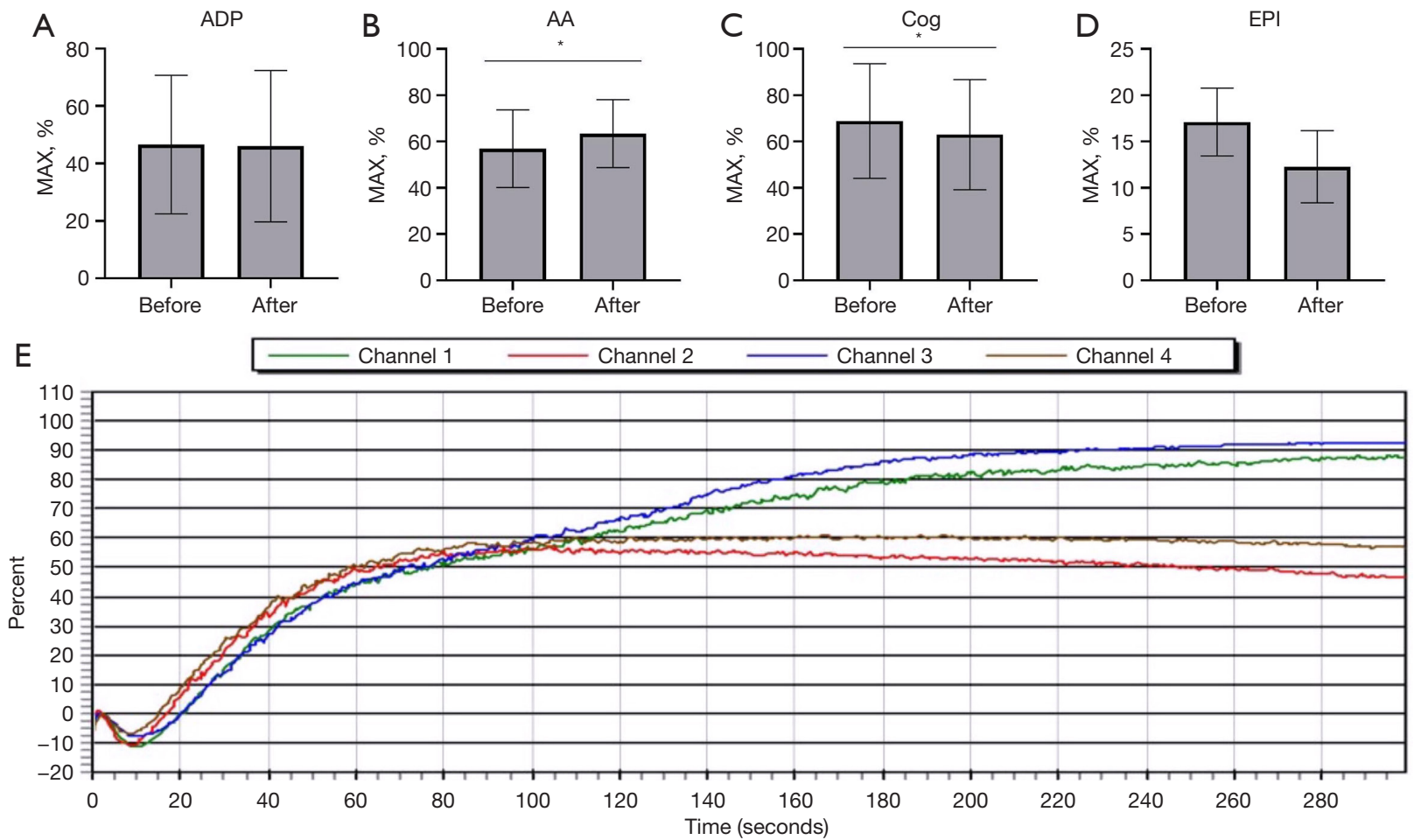

Figure 4 Platelet aggregation function test. (A) Adenosine diphosphate (ADP) activator. (B) Arachidonic acid (AA) activator. (C) Collagen (Cog) activator. (D) Epinephrine (EPI) activator. (E) Trend diagram before and after $16.9 \mathrm{~J} / \mathrm{cm}^{2}$ treatment for 2 samples (before treatment: Channel 1 and Channel 3; after treatment: Channel 2 and Channel 4). The error bars represent standard deviations. Significance of differences from $0 \mathrm{~J} / \mathrm{cm}^{2}$ for the corresponding cytokine is indicated by *, $\mathrm{P}<0.05$.

Blood System for Platelets, and the results showed that the inactivation efficacy of the INTERCEPT Blood System for Platelets was more effective for all bacteria tested at high or low titers, while The Mirasol Pathogen Reduction Technology system was less effective for the inactivation of $S$. aureus and Bacillus subtilis at low titers. Gravemann et al. (22) evaluated the inactivation of bacteria using the THERAFLEX UV-Platelets system and showed a mean logs reduction of 3.1 to 7.5 after treatment, indicating an effective inactivation of transfusion-related bacterial species in platelets.

We tested the effect on the main platelet parameters after the inactivation of bacteria in platelets by using this set of inactivation systems. After treatment with $16.9 \mathrm{~J} / \mathrm{cm}^{2}$ (exposure for 20 minutes) and higher doses, the difference in platelet count results was statistically significant, but there were no significant changes in MPV or PDW, suggesting that pathogen inactivation caused platelet destruction but had little effect on platelet volume. Subsequently, we measured the related blood gas parameters after treatment with $16.9 \mathrm{~J} / \mathrm{cm}^{2}$ (exposure for 20 minutes).
The results showed that there were differences in oxygen partial pressure and lactic acid content, suggesting that the treatment process might accelerate platelet metabolism. The results of platelet aggregation experiments after this dose treatment showed that there was no significant difference in platelet aggregation function between the ADP and EPI activator groups, while the platelet aggregation function was enhanced after treatment with the AA activator group, so platelet aggregation function was not decreased due to pathogen inactivation treatment. The results of TEG also confirmed this conclusion. After treatment with $16.9 \mathrm{~J} / \mathrm{cm}^{2}$ (exposure for 20 minutes), the MA values of the main reactive platelet function basically did not change. Studies have been conducted on the proteomics changes of platelets after treatment with 3 international methods. The results showed that the effects of the 3 methods seemed to be different: The Mirasol Pathogen Reduction Technology system affected platelet adhesion and shape change, while the INTERCEPT Blood System seemed to affect the protein of intracellular platelet activation pathway, and the THERAFLEX UV-Platelets system affected platelet shape 

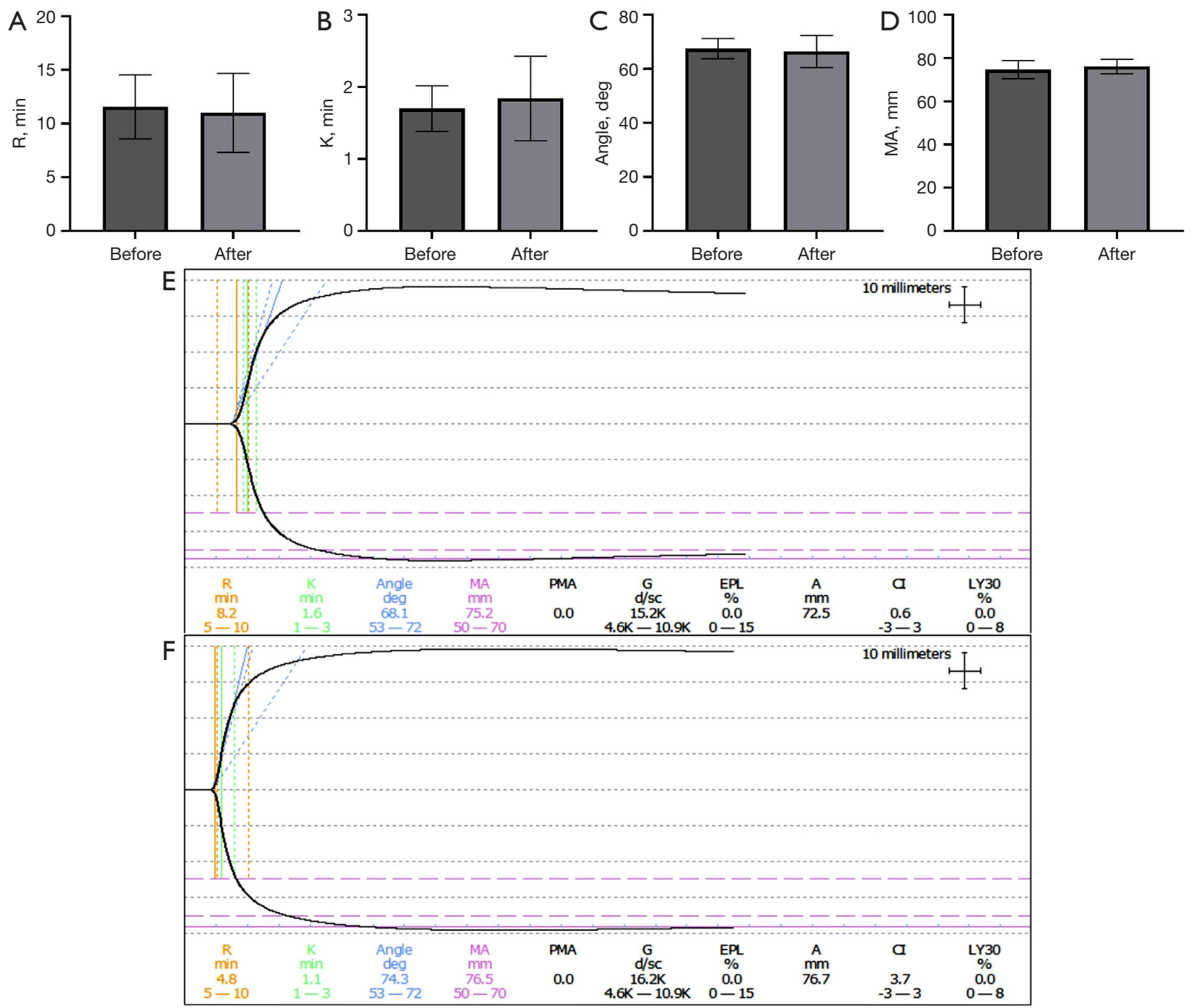

Figure 5 Thrombelastogram test results before and after treatment of $16.9 \mathrm{~J} / \mathrm{cm}^{2}$. (A) R value. (B) K value. (C) Angle. (D) MA value. (E) Trend diagram before treatment. (F) Trend diagram after treatment.

change and aggregation (23). It has also been found that after platelet pathogen inactivation treatment, the Mirasol Pathogen Reduction Technology system enhances the phosphorylation of vasodilator-stimulated phosphoprotein Ser-239 in platelets during storage, which may be related to the regulation of actin kinetics and integrin $\alpha\left({ }_{\mathrm{IIb}}\right) \beta\left({ }_{3}\right)$ activation, thus explaining the impact of the Mirasol Pathogen Reduction Technology system on in vitro mass measurement caused by platelet pathogen inactivation treatment (24). Perez-Pujol et al. (25) evaluated the effect of platelet pathogen inactivation on platelet function in the Mirasol Pathogen Reduction Technology system and found that after treatment with $6.2 \mathrm{~J} / \mathrm{mL}$, platelet adhesion and aggregation functions, major platelet glycoprotein $\left(\mathrm{GPI}_{\mathrm{b}-\alpha}\right.$, GPIV, and $\mathrm{GPII}_{b}-\mathrm{III}_{\mathrm{a}}$ ) and activation antigen [p-selectin and Lysosomal integral membrane protein (LIMP)] remained close to those of the control.

In conclusion, bacterial contamination remains a significant risk in patients requiring platelet transfusions. Optimization of donor screening, specification of the blood collection preparation process, and improvement of platelet bacterial contamination detection methods can significantly reduce the incidence of TTBI and STRs; nevertheless, the development of blood pathogen inactivation systems remains critical. Three types of products have been applied internationally, and no related products have been listed 
in China. This study has expanded and validated the inactivation effect of the previously independently developed pathogen inactivation system for blood components based on riboflavin photochemical method on platelet bacterial contamination and its impact on platelet quality. The results showed that the inactivation effect could meet the actual clinical needs and that the quality of platelets would not be significantly affected at the inactivation dose $\left(16.9 \mathrm{~J} / \mathrm{cm}^{2}\right)$. Therefore, the possibility of applying this system in inactivating bacterial contamination of platelets can be preliminarily confirmed. However, in view of the relatively small number of contaminating bacteria selected in this study and the fact that no research on platelet functionrelated proteins was involved, further studies are needed on the safety and effectiveness of inactivated platelets.

\section{Acknowledgments}

We thank for the technical support provided by the Microbiology Department of the General Hospital of the People's Liberation Army and the experimental support provided by the Biochemical Class of the General Hospital of the People's Liberation Army.

Funding: The study was supported by the Military Major Special Project for "the 13 th Five-year Plan" (No. BWS16J006-02), the CAMS Innovation Fund for Medical Sciences (CIFMS; No. 2017-I2M-3-021), the Innovation project of PLA General Hospital (No. CX19006), and the grants from National Natural Science Foundation of China (No. 81800127).

\section{Footnote}

Reporting Checklist: The authors have completed the MDAR reporting checklist. Available at https://dx.doi. org/10.21037/atm-21-5834

Data Sharing Statement: Available at https://dx.doi. org/10.21037/atm-21-5834

Conflicts of Interest: All authors have completed the ICMJE uniform disclosure form (available at https://dx.doi. org/10.21037/atm-21-5834). The authors have no conflicts of interest to declare.

Ethical Statement: The authors are accountable for all aspects of the work in ensuring that questions related to the accuracy or integrity of any part of the work are appropriately investigated and resolved. The Institutional Ethics Committee of Chinese PLA General Hospital (CPGH) approved this study (No. S2020-270-01). The study was conducted in accordance with the Declaration of Helsinki (as revised in 2013). There are no clinical subjects involved in this study, so there is no need to provide informed consent.

Open Access Statement: This is an Open Access article distributed in accordance with the Creative Commons Attribution-NonCommercial-NoDerivs 4.0 International License (CC BY-NC-ND 4.0), which permits the noncommercial replication and distribution of the article with the strict proviso that no changes or edits are made and the original work is properly cited (including links to both the formal publication through the relevant DOI and the license). See: https://creativecommons.org/licenses/by-nc-nd/4.0/.

\section{References}

1. Adam EH, Fischer D. Plasma Transfusion Practice in Adult Surgical Patients: Systematic Review of the Literature. Transfus Med Hemother 2020;47:347-59.

2. Levy JH, Neal MD, Herman JH. Bacterial contamination of platelets for transfusion: strategies for prevention. Crit Care 2018;22:271.

3. Warner MA, Chandran A, Frank RD, et al. Prophylactic Platelet Transfusions for Critically Ill Patients With Thrombocytopenia: A Single-Institution PropensityMatched Cohort Study. Anesth Analg 2019;128:288-95.

4. Yin W, Wang Y, Liu L, et al. Biofilms: The Microbial "Protective Clothing" in Extreme Environments. Int J Mol Sci 2019;20:3423.

5. Savinkina AA, Haass KA, Sapiano MRP, et al. Transfusionassociated adverse events and implementation of blood safety measures - findings from the 2017 National Blood Collection and Utilization Survey. Transfusion 2020;60 Suppl 2:S10-6.

6. Hong H, Xiao W, Lazarus HM, et al. Detection of septic transfusion reactions to platelet transfusions by active and passive surveillance. Blood 2016;127:496-502.

7. Lanteri MC, Santa-Maria F, Laughhunn A, et al. Inactivation of a broad spectrum of viruses and parasites by photochemical treatment of plasma and platelets using amotosalen and ultraviolet A light. Transfusion 2020;60:1319-31.

8. Ragan I, Hartson L, Pidcoke H, et al. Pathogen reduction of SARS-CoV-2 virus in plasma and whole blood using 


\section{Page 10 of 10}

riboflavin and UV light. PLoS One 2020;15:e0233947.

9. Rustanti L, Hobson-Peters J, Colmant AMG, et al. Inactivation of Japanese encephalitis virus in plasma by methylene blue combined with visible light and in platelet concentrates by ultraviolet $\mathrm{C}$ light. Transfusion 2020;60:2655-60.

10. Giannella M, Bartoletti M, Gatti M, et al. Advances in the therapy of bacterial bloodstream infections. Clin Microbiol Infect 2020;26:158-67.

11. Corean J, Al-Tigar R, Pysher T, et al. Quality Improvement After Multiple Fatal TransfusionTransmitted Bacterial Infections. Am J Clin Pathol 2018;149:293-9.

12. Kundrapu S, Srivastava S, Good CE, et al. Bacterial contamination and septic transfusion reaction rates associated with platelet components before and after introduction of primary culture: experience at a US Academic Medical Center 1991 through 2017. Transfusion 2020;60:974-85.

13. Schibilsky D, Driessen A, White WJ, et al. Traumatic tracheobronchial injuries: incidence and outcome of 136.389 patients derived from the DGU traumaregister. Sci Rep 2020;10:20555.

14. Garraud O, Cognasse F, Tissot JD, et al. Improving platelet transfusion safety: biomedical and technical considerations. Blood Transfus 2016;14:109-22.

15. Kern WV, Rieg S. Burden of bacterial bloodstream infection-a brief update on epidemiology and significance of multidrug-resistant pathogens. Clin Microbiol Infect 2020;26:151-7.

16. Prax M, Bekeredjian-Ding I, Krut O. Microbiological Screening of Platelet Concentrates in Europe. Transfus Med Hemother 2019;46:76-86.

17. Vollmer T, Hinse D, Diekmann J, et al. Extension of the
Storage Period of Platelet Concentrates in Germany to 5 Days by Bacterial Testing: Is it Worth the Effort? Transfus Med Hemother 2019;46:111-3.

18. Zenati F, Barguigua A, Nayme K, et al. Characterization of uropathogenic ESBL-producing Escherichia coli isolated from hospitalized patients in western Algeria. J Infect Dev Ctries 2019;13:291-302.

19. Haass KA, Sapiano MRP, Savinkina A, et al. TransfusionTransmitted Infections Reported to the National Healthcare Safety Network Hemovigilance Module. Transfus Med Rev 2019;33:84-91.

20. Akova M. Epidemiology of antimicrobial resistance in bloodstream infections. Virulence 2016;7:252-66.

21. Kwon SY, Kim IS, Bae JE, et al. Pathogen inactivation efficacy of Mirasol PRT System and Intercept Blood System for non-leucoreduced platelet-rich plasma-derived platelets suspended in plasma. Vox Sang 2014;107:254-60.

22. Gravemann U, Handke W, Müller TH, et al. Bacterial inactivation of platelet concentrates with the THERAFLEX UV-Platelets pathogen inactivation system. Transfusion 2019;59:1324-32.

23. Prudent M, D'Alessandro A, Cazenave JP, et al. Proteome changes in platelets after pathogen inactivation--an interlaboratory consensus. Transfus Med Rev 2014;28:72-83.

24. Schubert P, Culibrk B, Coupland D, et al. Riboflavin and ultraviolet light treatment potentiates vasodilatorstimulated phosphoprotein Ser-239 phosphorylation in platelet concentrates during storage. Transfusion 2012;52:397-408.

25. Perez-Pujol S, Tonda R, Lozano M, et al. Effects of a new pathogen-reduction technology (Mirasol PRT) on functional aspects of platelet concentrates. Transfusion 2005;45:911-9.
Cite this article as: Fan B, Yi M, Yang G, Yang L, Shang W, Liu Y, Zhong X, Zhu L, Wang D. Expanded validation of the effect and quality of a pathogen inactivation system based on riboflavin photochemistry on platelet bacterial contamination. Ann Transl Med 2021;9(23):1736. doi: 10.21037/atm-21-5834 